\title{
Sources of Verticillium dahliae Affecting Lettuce
}

\author{
Zahi K. Atallah, Karunakaran Maruthachalam, and Krishna V. Subbarao
}

Department of Plant Pathology, University of California, Davis, c/o U.S. Agricultural Research Station, 1636 E. Alisal Street, Salinas 93905. Current address of Z. K. Atallah: Center for Advanced Technology, Hartnell College, 411 Central Ave., Salinas, CA 93901.

Accepted for publication 17 July 2012.

\section{ABSTRACT}

Atallah, Z. K., Maruthachalam, K., and Subbarao, K. V. 2012. Sources of Verticillium dahliae affecting lettuce. Phytopathology 102:1071-1078.

Since 1995, lettuce in coastal California, where more than half of the crop in North America is grown, has consistently suffered from severe outbreaks of Verticillium wilt. The disease is confined to this region, although the pathogen (Verticillium dahliae) and the host are present in other crop production regions in California. Migration of the pathogen with infested spinach seed was previously documented, but the geographic sources of the pathogen, as well as the impact of lettuce seed sparsely infested with $V$. dahliae produced outside coastal California on the pathogen population in coastal California remain unclear. Population analyses of $V$. dahliae were completed using 16 microsatellite markers on isolates from lettuce plants in coastal California, infested lettuce seed produced in the neighboring Santa Clara Valley of California, and spinach seed produced in four major spinach seed production regions: Chile, Denmark, the Netherlands, and the United States (Washington State). California produces $80 \%$ of spinach in the United States and all seed planted with the majority infested by $V$. dahliae comes from the above four sources. Three globally distributed genetic populations were identified, indicating sustained migration among these distinct geographic regions with multiple spinach crops produced each year and repeated every year in coastal California. The population structure of $V$. dahliae from coastal California lettuce plants was heavily influenced by migration from spinach seed imported from Denmark and Washington. Conversely, the sparsely infested lettuce seed had limited or no contribution to the Verticillium wilt epidemic in coastal California. The global trade in plant and seed material is likely contributing to sustained shifts in the population structure of $V$. dahliae, affecting the equilibrium of native populations, and likely affecting disease epidemiology.
Verticillium wilt has plagued the production of numerous small fruit and vegetable crops in the Central Coast region of California (Monterey, Santa Cruz, San Benito, and Santa Clara counties) for decades $(14,40)$, with the exception of lettuce (Lactuca sativa L.) that remained immune to the disease until the mid-1990s. Verticillium wilt first appeared on lettuce in 1995 and the crop has since suffered consistently from this disease $(3,37)$. Since the initial discovery of the disease on lettuce, the causes of this host range expansion of the causal agent (Verticillium dahliae) into lettuce have led to intense research and debate. The migration of $V$. dahliae with infested spinach seed was suggested as a major factor in the appearance of Verticillium wilt on lettuce. Isolates of $V$. dahliae from spinach seed were subsequently proven to be virulent and aggressive on lettuce (4). Rotations between spinach and lettuce routinely occur in coastal California. California accounts for nearly $80 \%$ of the U.S. spinach production (2). However, all spinach seed planted in this region comes from outside of California, because the latitude of state does not allow for the 18-h day length required to trigger flowering in spinach plants. Thus, spinach seed production is restricted to far northern and southern latitudes, including the U.S. Pacific Northwest where nearly $50 \%$ of the United States and $20 \%$ of the annual world supply of spinach seed is produced, and the remainder is produced in countries such as Chile, Denmark (largest producer), The Netherlands, and New Zealand. Pathogens endemic in these production regions including $V$. dahliae have the potential to be transported with seed that is planted in California. Even though spinach is a known host of $V$. dahliae $(13,35,36)$, inoculum borne on or in spinach seed does not affect spinach crops because they are harvested within 4 weeks after planting, well before flowering, when Verticillium

Corresponding author: K. V. Subbarao; E-mail address: kvsubbarao@ucdavis.edu

http://dx.doi.org/10.1094/PHYTO-04-12-0067-R

(C) 2012 The American Phytopathological Society wilt symptoms generally manifest themselves in most crops. However, the pathogen was recovered from spinach plants soon after emergence, and from the seed used to produce spinach crops (unpublished data). Thus, V. dahliae introduced on spinach seed becomes part of the soil fungal community affecting crops that follow spinach including lettuce (4).

The pathogen is both internally and externally seedborne in spinach carrying an average of 200 to 300 microsclerotia per individual spinach seed (K. Maruthachalam and K. V. Subbarao, unpublished data). The pathogen is also seedborne in lettuce, but lettuce seed does not harbor microsclerotia (38). In 62 spinach seed lots tested for $V$. dahliae, up to $85 \%$ incidence was reported (13), whereas the highest incidence was less than 5\% among 265 tested lettuce seed lots (3). Consequently, compared with the 370,000 lettuce seeds planted per hectare, up to 9 million spinach seeds are planted; the likelihood of introducing and establishing $V$. dahliae in a commercial field by planting infested spinach seed is considerably higher than with lettuce seed.

Currently, with the exception of two reports from Europe $(17,22)$, Verticillium wilt on lettuce has, thus far, only been observed in and reported from the central coastal California, although both $V$. dahliae and lettuce are far more ubiquitous in California, and elsewhere. The causes that confine the disease on lettuce to this production region are unknown, in spite of the similarities in agricultural production practices in neighboring regions of California and Arizona. Furthermore, California produces nearly $80 \%$ of the spinach grown in North America (2). In 62 spinach seed lots tested for $V$. dahliae, up to $85 \%$ incidence was reported (13), whereas the highest incidence was less than 5\% among 265 tested lettuce seed lots (3).

The populations of $V$. dahliae from various hosts in coastal California (strawberry, pepper, artichoke, etc.) were undifferentiated from the lettuce population. Furthermore, these populations were not differentiated from isolates obtained from spinach seed produced in the U.S. Pacific Northwest and northern Europe. 
However, the exact geographic origin(s) of the migrant genotypes from the various spinach seed production regions was not resolved. In addition, whether the populations obtained from lettuce seed, which is produced in California, are a source of such migrant genotypes has also not been determined.

To determine the relative contributions of the potential source(s) of $V$. dahliae migrant genotypes that affect lettuce (and other hosts) in coastal California, we investigated in this study the population structures of, and immigration from, five potential sources of the pathogen. These included populations from lettuce seed produced in the Santa Clara Valley in California, and spinach seed produced in four major spinach seed production regions in Europe and North and South America. We also attempted to estimate the time since divergence between differentiated populations (or lineages) to potentially correlate it with historical agricultural trends or events.

\section{MATERIALS AND METHODS}

Isolate collection and DNA extraction. Two hundred and ninety isolates of $V$. dahliae were included in this study (Table 1). Sixty-five isolates were from infected lettuce plants from coastal California (Salinas and Pajaro river valleys). Collections and isolations were carried out between 1995 and 2007 in commercial fields where Verticillium wilt had occurred. As stated above, the disease is restricted to this area in the United States and consequently sampling of isolates from infected lettuce was also restricted to this area. Analyses using simple sequence repeats (SSRs), intergenic spacer (IGS) rDNA sequences, amplified fragment length polymorphism (AFLPs), and virulence suggested a lack of differentiation among the various sampling dates. Therefore, all V. dahliae isolates from coastal California lettuce were concatenated into one sampling group.

One hundred and sixty-nine isolates were from spinach seed produced in the U.S. state of Washington $(n=54)$, Denmark $(n=$ $38)$, The Netherlands $(n=32)$, and Chile $(n=45)$. These seed lots were destined for planting in coastal California and other spinach production regions. Isolates derived from three seed lots were used from each spinach seed source. Additionally, 56 isolates included in this study were from lettuce seed produced in the Santa Clara Valley of California, which is contiguous with the Salinas and Pajaro river valleys (where the majority of the commercial lettuce and spinach crops are produced in the United States). The isolates were derived from three different lettuce seed lots produced in one geographic area.

Mycelia were harvested from potato dextrose broth cultures and total DNA was extracted using DNeasy Plant Mini Kit (Qiagen, Valencia, CA). Extracted DNA was quantified using a NanoDrop 1000 spectrophotometer (NanoDrop Products, Wilmington, DE) and concentrations were standardized to $2 \mathrm{ng} / \mu \mathrm{l}$ by dilution in autoclaved purified water (Milli-Q, Millipore, Billerica, MA). DNA samples were kept at $4^{\circ} \mathrm{C}$ until used.

SSR amplifications. Primers amplifying the following 16 SSR loci were employed: VD1, VD2, VD3, VD7, VD9, VD11, VD12,
VD26, VD27, VD65, VD69, VD73, VD85, VD96, VD97, and VD98. These primers and targeted SSR loci were previously described (1) and were employed for the amplification of SSR loci. Polymerase chain reaction (PCR) assays were conducted to amplify individual loci. Reaction mixtures included 2 ng of DNA from $V$. dahliae, and GoTaq colorless PCR mix (Promega, Madison, WI), in 20- $\mu$ l reactions. Amplifications were performed in Bio-Rad DNA Engine thermocyclers (Bio-Rad Laboratories, Hercules, CA) and used the following cycling parameters: denaturing at $95^{\circ} \mathrm{C}$ for $2 \mathrm{~min}$, followed by 35 cycles of denaturing at $95^{\circ} \mathrm{C}$ for $10 \mathrm{~s}$, annealing at $58^{\circ} \mathrm{C}$ for $10 \mathrm{~s}$, and extension at $72^{\circ} \mathrm{C}$ for $30 \mathrm{~s}$. A final extension was carried out at $72^{\circ} \mathrm{C}$ for $5 \mathrm{~min}$. Subsequently, PCR fragments labeled with the four fluorophores were multiplexed for fragment analysis. A total of $1 \mu \mathrm{l}$ of each labeled PCR fragment was mixed with fragments labeled with the three remaining fluorophores. Then $1 \mu \mathrm{l}$ of this multiplex mixture was combined with Hi-Di formamide and $0.3 \mu \mathrm{l}$ of LIZ-500 size standard and separated on an ABI 3100 sequencer (Applied Biosystems, Foster City, CA). Fragment analysis was completed using the GeneMarker software (SoftGenetics, State College, PA).

General genetic information. The Ewens-Watterson neutrality test $(25,39)$ was completed using the software Arlequin version 3.11 (16), and Nei's gene diversity $\left(H_{\mathrm{obs}}\right)(24)$ was calculated using the software Genodive (23).

Population structure and identification of genetic clusters. The affiliation of individual isolates of $V$. dahliae to specific genetic clusters and the possibility of admixture were tested using the software Structure version 2.3 (31). A lack of significant differentiation between sampling groups may be explained by repeated migration. For each number of clusters $\mathrm{K}(\mathrm{K}=1$ through 6), defined as genetic clusters, 10 runs were performed with a burn-in period of 100,000 generations and 1,000,000 Markov Chain Monte Carlo (MCMC) simulations. The admixture model was chosen, and the loci were considered independent, in light of previous analyses that indicated a lack of linkage among loci. The analysis was repeated five times to ensure convergence of results.

The ad-hoc statistic $\Delta \mathrm{K}$ was computed (15) to estimate the most likely number of genetic clusters $\mathrm{K}$. This method uses the rate of change in the log probability between the successive $\mathrm{K}$ values. Accordingly, the results from Structure, were permuted and aligned in the program CLUMPP (21), and then plotted graphically using the software Distruct (34).

The potential for structuring within each genetic cluster identified was investigated using the principal coordinates analysis (PCA) in GenAlEx version 6.2 (28). For this, the structure was estimated within each cluster, and included the sampling groups based on the affiliation of their individual isolates to these clusters. Isolates were assigned to individual genetic clusters if the value of their calculated $Q$ was $>70 \%$. Sampling groups were only retained if a minimum of seven isolates were identified; otherwise the sampling group was removed from further analyses within the particular genetic cluster.

Migration analysis. In the absence of migration or given an extended history of genetic drift between pairs of populations,

TABLE 1. Host plant, origin, and type of host tissue from which Verticillium dahliae isolates were obtained, number of isolates used in the population analyses, Nei's corrected gene diversity $(H)(24)$, and Ewens-Watterson (EW) neutrality test (39)

\begin{tabular}{lllccc}
\hline Host & \multicolumn{1}{c}{ Origin } & Tissue type & Number of individuals & $H_{\mathrm{obs}^{\mathrm{a}}}$ & $\mathrm{EW}^{\mathrm{b}}(P$ value $)$ \\
\hline Spinach $^{\mathrm{c}}$ & Chile & Seed & 45 & 0.306 & 0.969 \\
& Denmark & Seed & 38 & 0.704 & 0.823 \\
& Netherlands & Seed & 32 & 0.465 & 1.000 \\
& Washington State, USA & Seed & 54 & 0.320 & 1.000 \\
Lettuce & Coastal California, USA & Symptomatic plants & 65 & 0.409 & 0.204 \\
& Santa Clara Valley, CA, USA & Seed & 56 & 0.845 \\
\hline
\end{tabular}

${ }^{\text {a }} H$ values were generated in Genodive (23).

${ }^{\mathrm{b}} \mathrm{EW}$ neutrality test was calculated in Arlequin (16).

${ }^{\mathrm{c}}$ Isolates were provided by L. du Toit (Washington State University) and S. Koike (University of California-Cooperative Extension). 
migration rates (specifically recent exchange) are expected to be low. Furthermore, it is suggested that the exchange of as few as one migrant per generation may be enough to hinder genetic drift between two populations (18). Owing to the continuous nature of the exchange of $V$. dahliae via movement of plant material among various geographic regions (4), it is reasonable to assume that equilibrium between the populations studied is not achieved. Therefore, the migration rates were studied using methods relying on different evolutionary models. The first approach relied on the coalescent approach using likelihood as implemented in Migrate version $3.0 .3(6,7)$. The second approach was implemented in GeneClass2 (30), and employed a test that excludes populations that are not likely to be the sources of the individual genotypes tested (10). Using the exclusion approach allows for testing the source of migrant genotypes, while acknowledging that not all possible source populations were included in the analysis (29). Two simulation methods were compared for this exclusion method. (i) A migrant assignment method relying on a Bayesian approach to place genotypes into possible source populations based on allele frequencies (33). (ii) A Monte-Carlo-based resampling method by Paetkau et al. (27) that generates hypothetical gametes rather than alleles, hence reducing the type I error rate, while modeling populations processes more faithfully than other methods $(9,32)$. Furthermore, the probability of finding first-generation immigrants was explored in GeneClass2 (30), by applying the $\mathrm{L}_{\mathrm{h}} / \mathrm{L}_{\max }$ likelihood ratio with the Paetkau et al. (27) resampling method, while applying $\alpha=0.01$ as critical threshold level. One known weakness of this method lies in its assumption that all possible source populations were sampled. The genetic clusters identified in the Structure analysis, and the sampling groups within each genetic cluster, were used in all of the migration tests. In such a case, gene flow and mutation would be considered the sole contributors of novel alleles to each population.

The software Migrate version 3.0.3 (http://popgen.scs.fsu.edu) was used to estimate the effective population size $(\Theta$, defined as the size of an "ideal" population) and interpopulation migration $(6,7)$. Analyses of asymmetrical migration are possible in Migrate, as the method does not assume symmetrical rates of migration. Mutation rates at all 16 SSR loci were assumed to be constant for estimating migration rates. Five independent runs (a different random seed was chosen each time) were performed using the Brownian motion model, and the results of the run that generated the smallest $\operatorname{Ln}$ (Likelihood) value. Five short chains were performed with 1,000 samples and 20 sampling increments and 1,000 trees were recorded; whereas, five long chains were performed with 5,000 samples, a burn-in of 10,000, and 5,000 trees were recorded. Heating was applied using four different temperatures $(1,1.5,3$, and 9 degrees).
The exclusion test of Cornuet et al. (10) was performed in the software GeneClass2 (30). A total of 10,000 simulated individuals were generated for each sampling group, and the confidence level was set at 0.01. Five independent runs were completed with the Bayesian resampling method of Rannala and Mountain (33) and with the frequency-based resampling method of Paetkau et al. (27). The percentage of individuals that could not be excluded from each population is shown.

Divergence time. The estimation of divergence time between the lettuce plant population from coastal California and the lettuce seed population from the Santa Clara Valley was performed using the software IM $(19,20,26)$. This isolation by migration algorithm is particularly aimed at populations that have recently diverged from a common ancestor. And through a Bayesian analysis allows the evaluation of demographic models with varying levels of population size, migration rate, and divergence time.

Given that population sizes $(\theta)$ were similar using Migrate analysis and that all were exhibiting growth (data not shown), it was deemed appropriate to assume constant population size following divergence. Posterior distributions were calculated for $\theta, \mathrm{m}$, and $\mathrm{t}$, by applying a Metropolis Coupled Markov Chain Monte-Carlo (MCMCMC) with 10,000,000 simulations, a burn-in time of $1,000,000$, five heated chains, and a geometric heating scheme. The scalars for maximum $\theta, \mathrm{m}$, and $\mathrm{t}$ values were chosen after multiple preliminary runs and they were $\mathrm{q} 1=10, \mathrm{~m} 1=1$, $\mathrm{m} 2=1$, and $\mathrm{t}=10$, respectively. Five independent runs with varying seed numbers and convergent posterior distributions were completed. A mutation rate $(\mu)$ of $1.39 \times 10^{-5}$ per locus per year was applied to locus VD2, and isolation with migration (IM) calculated the corresponding mutation rates for the remaining loci. This value of $\mu$ was obtained from the estimation of mutation rate of SSR loci in Neurospora spp. (11). Based on the number of lettuce crops produced in coastal California, it was assumed that three generations of $V$. dahliae occur per year $(\mu=3)$.

\section{RESULTS}

However, varying levels of clonality were observed in the spinach and lettuce seed sampling groups (Table 1). Clones were identified among isolates from seeds collected from different seed lots, as well as among isolates from seeds within a seed lot. All of the population analyses were performed after clone-correction within each sampling group. No evidence of positive selection was concluded from the Ewens-Watterson neutrality test (Table 1).

Three genetic clusters spread among various geographic regions. Three distinct genetic clusters $(K=3)$ were identified among the six sampling groups included in this study. The rate of change in the log probability between the successive $\mathrm{K}$ values was highest for three genetic clusters $(\Delta \mathrm{K}=3158.7)$ compared
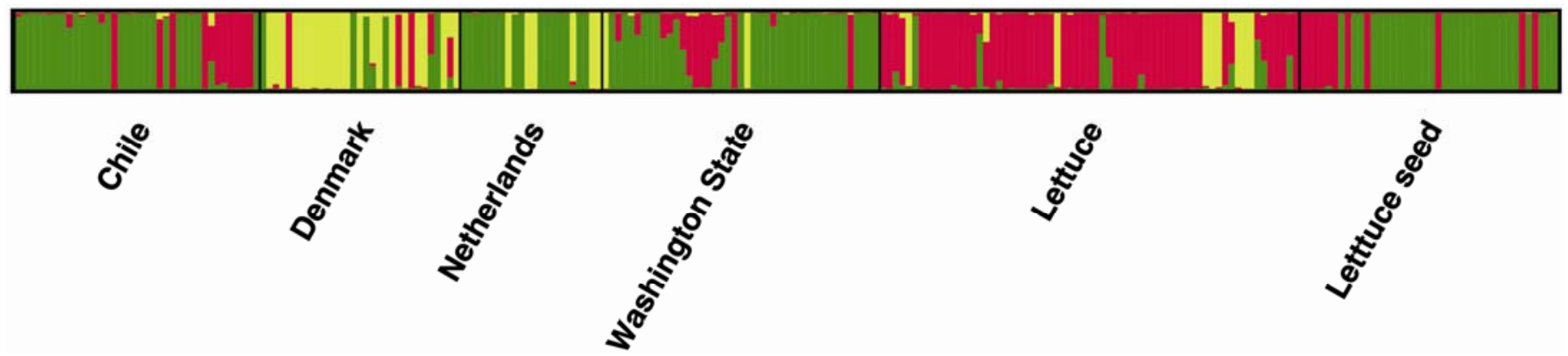

Fig. 1. Affiliation of individual genotypes of Verticillium dahliae as assessed using 16 polymorphic simple sequence repeat loci as measured in Structure version 2.3 (31). Individual haplotypes are separated into discrete vertical bars that are organized by sampling groups. Differences in color within a vertical bar indicate a multi-population affiliation of an individual genotype (admixture). The height of each color within an individual is the measure of proportional affiliation. $\mathrm{K}=3$ was determined to be the most likely number of genetic clusters for six Verticillium dahliae sampling groups from lettuce plants grown in coastal California, spinach seed from Europe and North and South America, and lettuce seed from the Santa Clara Valley of California. Cluster $1=$ red, Cluster $2=$ yellow, and Cluster $3=$ green. 
with any other $\mathrm{K}$ value tested $(\Delta \mathrm{K}<87)$. All three clusters were recovered in varying levels from the four spinach sampling groups, the green cluster predominated in the lettuce sampling group, while the red population predominated in the lettuce seed sampling group. The red cluster (hereafter referred to as genetic cluster 1) was particularly prevalent in Chile, The Netherlands, Washington, and lettuce seed sampling groups. The yellow cluster (hereafter referred to as genetic cluster 2) was recovered from Denmark, lettuce, and The Netherlands (six individuals only) sampling groups. And finally the green cluster (hereafter referred to as genetic cluster 3) was identified in the lettuce, Chile, and Washington sampling groups (Fig. 1). These results suggest that significant amounts of admixture occur among several sampling groups.

No significant differentiation was calculated between the Denmark spinach seed and lettuce sampling groups within genetic cluster 2 in the PCA analysis. In contrast, the lettuce seed sampling group was significantly differentiated from other sampling groups in both genetic clusters 1 and 3 (Fig. 2). And the lettuce sampling group was not differentiated from the Chile and Washington spinach sampling groups in genetic cluster 3. No differentiation was observed among the spinach seed sampling groups from Chile, The Netherlands, and Washington in genetic cluster 1. Similarly, no significant differentiation was measured between the spinach seed sampling groups from Chile and Washington in genetic cluster 3 .

Estimated population size and migration. The means of the $\Theta$ estimators of the effective population sizes were 1.05 for genetic cluster $1,1.31$ for cluster 2, and 1.16 for cluster 3 (data not shown). No significant difference was detected between the calculated $\Theta$ values of clusters 2 and 3 , whereas the $\Theta$ of cluster 1 was significantly different.

The analysis of migration using the coalescent approach implemented in Migrate indicated that the highest migration was between genetic clusters 1 and 3, which exceeded one migrant per generation in both directions (Fig. 3). Conversely, the migration rates between genetic cluster 2 and the other two clusters were significantly smaller than one migrant per generation. Within genetic cluster 1 , the lettuce seed sampling group consistently exchanged fewer than 0.7 migrants per generation with Chile, The

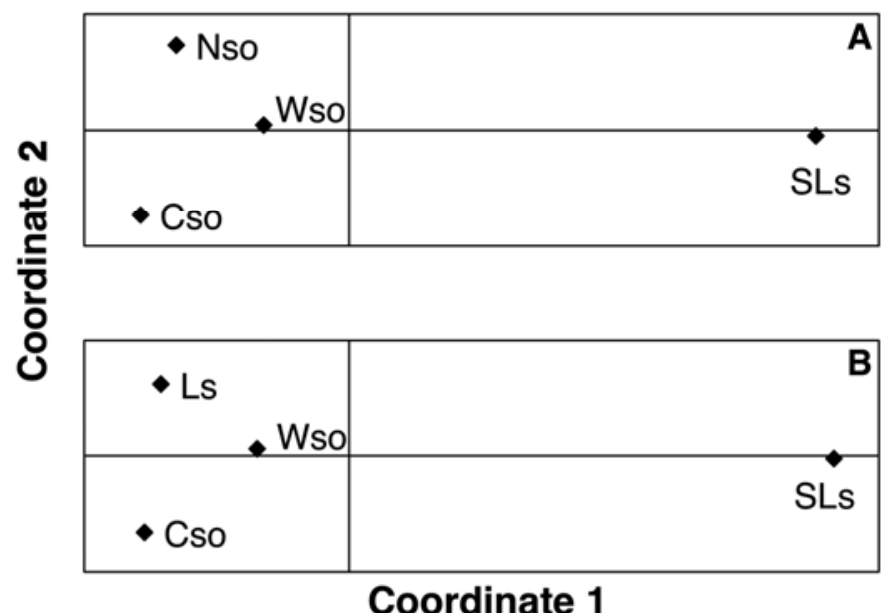

Fig. 2. Principal coordinates analysis of Verticillium dahliae from six sampling groups and subdivided into three genetic clusters based on the affiliation of individual isolates. The analysis was performed in GenAlEx version 6.2 (28) and only two principal components were detected. Only the analyses from $\mathbf{A}$, genetic cluster 1 (shown in red in Fig. 1) and $\mathbf{B}$, genetic cluster 3 (shown in green in Fig. 1) are shown, as there was no significant difference between the two sampling groups within genetic cluster 2 (shown in yellow in Fig. 1). Cso = spinach seed from Chile; Ls = lettuce plants from coastal California; Nso = spinach seed from the Netherlands; SLs = lettuce seed from Santa Clara Valley, California; and Wso = spinach seed from Washington State.
Netherlands, and Washington spinach seed sampling groups (Fig. $3)$. In contrast, all three spinach seed sampling groups exchanged more than one migrant per generation, with the exception of evidence of a unidirectional migration from The Netherlands into Washington. In genetic cluster 3, only the Washington spinach seed sampling group contributed 1.5 migrants per generation to the lettuce sampling group, whereas the latter only contributed 0.5 migrants to the former (Fig. 3). The remaining pairwise comparisons among the four sampling groups within cluster 3 yielded less than 0.7 migrants per generation.

The haplotype assignment tests by exclusion of Cornuet et al. (10) were not significantly different regardless of whether Bayesian (33) or frequency-based (27) resampling methods were employed. Strikingly, in the lettuce seed sampling group that comprises isolates affiliated with genetic clusters 1 and 3 , all assigned genotypes were from lettuce seed, and did not include any isolates from other sampling groups (Fig. 4). In each of the three genetic clusters, the majority of genotypes were recruited from within a sampling group. However, there was one exception in genetic cluster 1, where more genotypes from The Netherlands sampling group were assigned to the Washington sampling group.

In genetic cluster 1 , evidence of significant migration was found among all three spinach seed sampling groups, especially from Washington, a large spinach seed producer (Fig. 4A). For instance, 53 and $87 \%$ of genotypes from Chile and The Netherlands, respectively, were assigned to Washington, and $73 \%$ of Washington genotypes were self-recruited. The Netherlands sampling group was assigned 15 and $30 \%$ of genotypes from Chile and Washington, respectively, and only $62 \%$ were selfassigned. In contrast, Chile contributed 6 and $8 \%$ of the genotypes of The Netherlands and Washington sampling groups. In genetic cluster $2,75 \%$ of the genotypes in the lettuce sampling group were assigned to Denmark (Fig. 4B). And in genetic cluster 3 , $14 \%$ of the genotypes in the lettuce sampling group were assigned to Washington (Fig. 4C).

Divergence time. The time of divergence of the $V$. dahliae from lettuce in coastal California and lettuce seed from the Santa Clara Valley was in the range of 58,000 to 68,000 years ago. And the mean divergence time was ca. 64,000 years ago.

\section{DISCUSSION}

The population structure of the soilborne fungus $V$. dahliae, which affects lettuce production in coastal California, was influenced by the international trade in spinach seed infested with $V$. dahliae. Conversely, lettuce seed that is sporadically infested with $V$. dahliae (highest recorded incidence of $<5 \%$ ), and is produced $<60 \mathrm{~km}$ away, had limited or no impact on the structure of the pathogen population in commercial lettuce production in coastal California. Previous studies using SSR markers (4) and rDNA sequences and AFLP loci (5) had highlighted the ongoing migration of $V$. dahliae from spinach into lettuce, and other crops grown in coastal California. However, the actual sources of this immigration from the various spinach production regions were not identified, and the potential impact of infested lettuce seed on the epidemic was also uncertain. The current study clarifies the actual sources of migrant genotypes of $V$. dahliae causing wilt on lettuce in coastal California. This information may also help clarify the basis of the confinement of Verticillium wilt on lettuce to coastal California (the leading producer of lettuce and fresh spinach), with no evidence of its occurrence in other parts of the state or the United States.

Three distinct genetic clusters were identified across all six sampling groups, and were distributed pan-globally, suggesting migration among the various geographic regions and/or hosts of $V$. dahliae. Spinach seed is multiplied in various geographic locations, but significant germplasm redistribution occurs among such locations. Infested material therefore may easily be planted 
in a number of different regions at once. Since the vast majority of all spinach seed is sourced from the studied geographic areas for commercial spinach crop production in California and elsewhere, infested seed material likely spreads $V$. dahliae genotypes wherever this seed is planted. Correspondingly, the structure analysis suggests that the lettuce plant sampling group shared significant similarity to spinach groups from Denmark and Washington. These sources are ranked 1 and 2 in global spinach seed production (12). Furthermore, migration analyses confirmed that the similarity in structures was associated with the significance of migration from these two sources. In genetic cluster 2, no differentiation was observed between Denmark and coastal California, and $75 \%$ of the genotypes in the lettuce sampling group were assigned to Denmark. Similarly, in genetic cluster 3, $1.52 \mathrm{mi}-$ grants emigrated every generation from Washington to coastal California. The scale of this migration potentially hindered trends toward genetic drift due to allopatry.
In contrast to the lack of differentiation with spinach seed, the coastal California lettuce sampling group was significantly differentiated from the Santa Clara Valley lettuce seed sampling group. No evidence of migration was measured between lettuce seed and the remaining five sampling groups. Evidently, lineages of $V$. dahliae from lettuce seed and plants likely diverged long ago (ca. ancient divergence time 64,000 years). This timeframe precedes agriculture, and likely human presence in North America and is a reflection of the impact of the industrialized global agriculture of coastal California, whereby the equilibrium between drift and migration is regularly disturbed by the immigration of novel $V$. dahliae genotypes.

The observed lack of migration between contiguous California valleys indicates of the negligible role played by wind-blown conidia/microsclerotia, or bodies of water moving microsclerotia across the valleys. With Phaeosphaeria nodorum (the causal agent of glume blotch of wheat), the genetic analyses could not

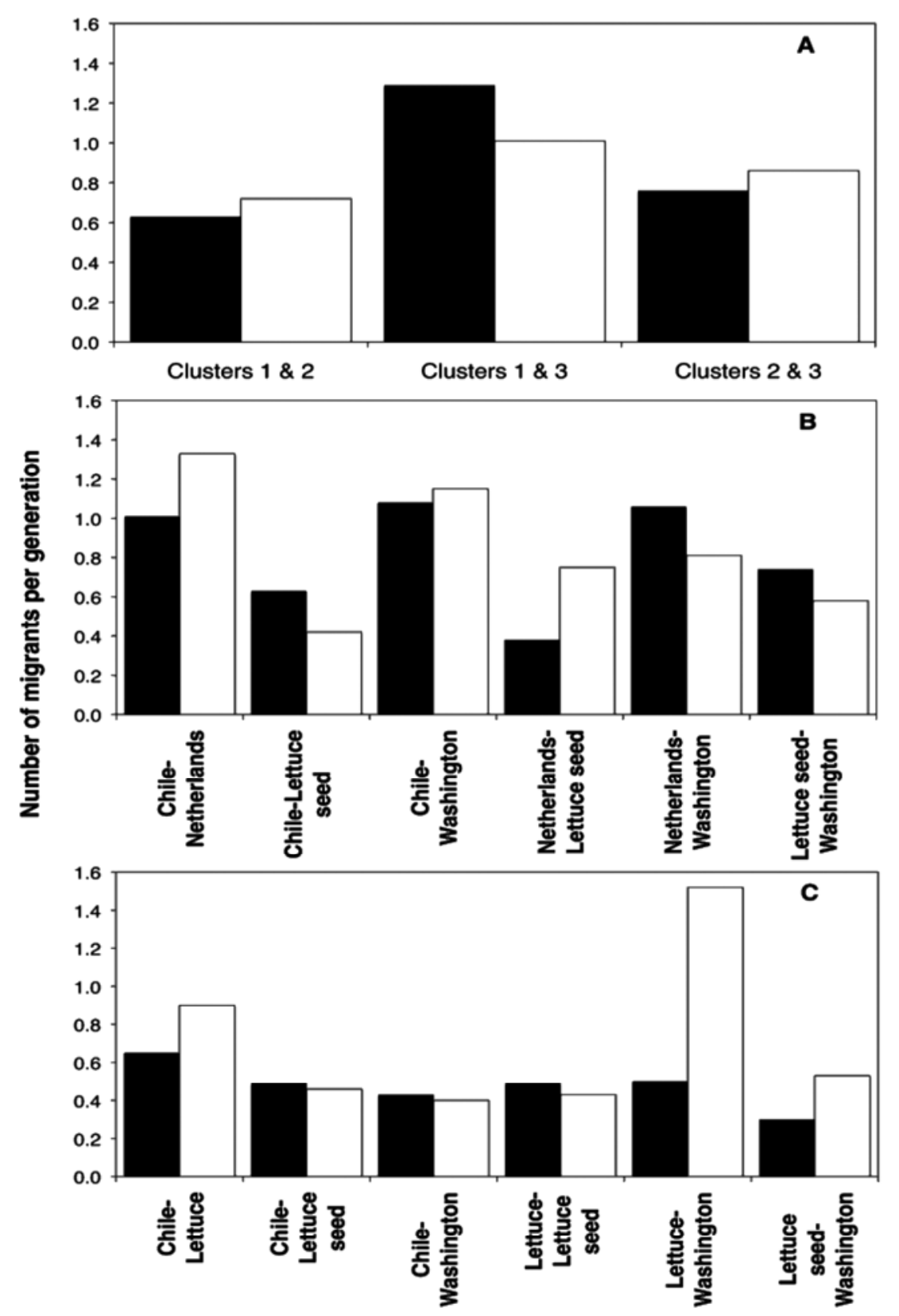

Fig. 3. Number of Verticillium dahliae migrants per generation calculated in Migrate $(6,7)$ for $\mathbf{A}$, pairs of genetic clusters and $\mathbf{B}$, pairs of sampling groups within genetic cluster 1 (shown in red in Fig. 1) and $\mathbf{C}$, pairs of sampling groups within genetic cluster 3 (shown in green in Fig. 1). Because Migrate produces bidirectional migrant estimates, two columns per sampling group, or genetic cluster, pairs are displayed. The black column exhibits the migration from population 2 into population 1 , whereas the white column shows the opposite migration. 


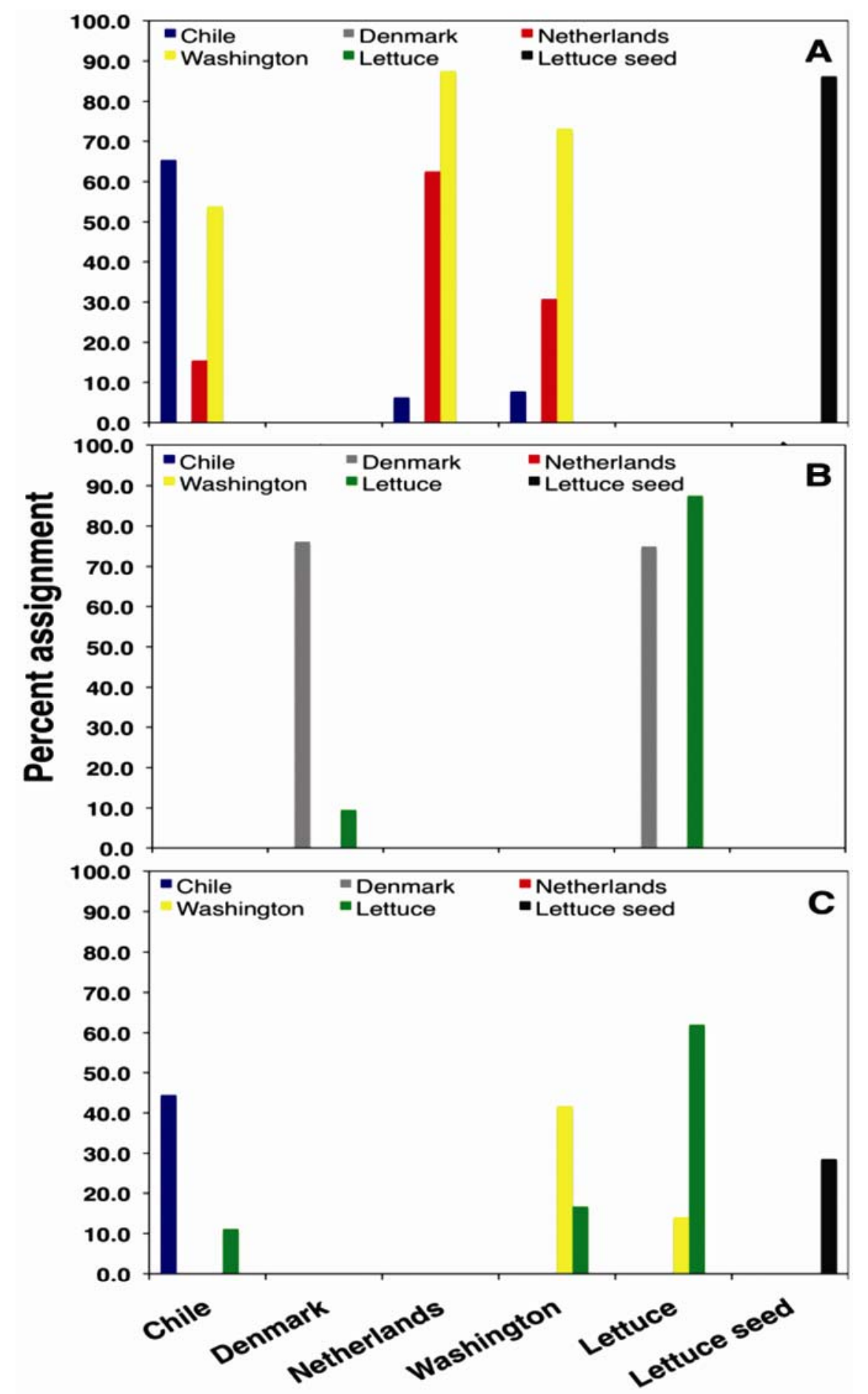

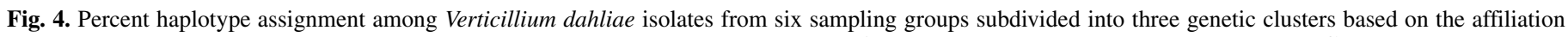

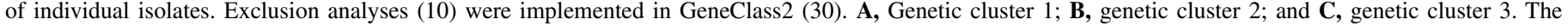
abscissa indicates receiving sampling groups, whereas colored columns indicate the proportion of genotypes associated with donor sampling groups.

exclude aerial spores as sources of inoculum, even if sources were separated by significant distances (8). Conversely, no evidence was found to support the hypothesis of aerial dispersal of Rhynchosporium secalis (the causal agent of barley scald) by ascospores over large distances (41).

This current research revealed significant genotype transfer between the spinach seed production regions in Chile, The Netherlands, and Washington State. However, there is little evidence of significant exchange between these three regions and Denmark. This is particularly interesting, given that $\approx 70 \%$ of the world spinach seed production is located on a small number of Danish islands, where common rotational crops include potato (another host for $V$. dahliae) and cereals (asymptomatic hosts for $V$. dahliae) (12). Additionally, the population of $V$. dahliae in Denmark was determined to have undergone a bottleneck in its history (data not shown), while the Nei's gene diversity index (24) was highest for this population $\left(H_{\mathrm{obs}}=0.704\right)$. It is possible that these observations may be due to a phenomenon similar to the island model effect (18).

At this time, we have no knowledge of the population status of $V$. dahliae from coastal California outside of agriculture, which precludes our ability to discern the impact of the massive flow of infested spinach seed from the original indigenous population. However, genotypes imported with spinach seed are commonly 


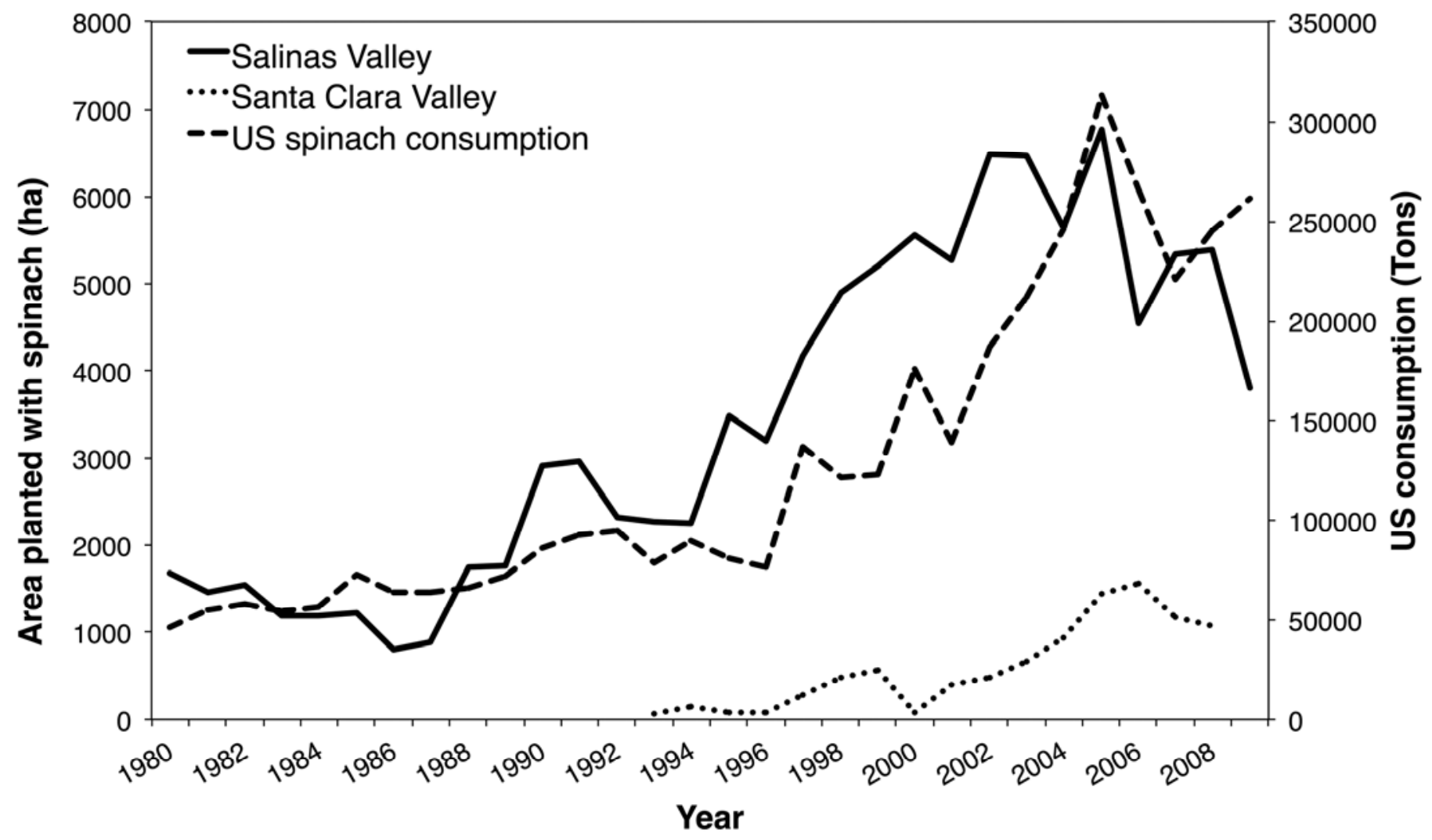

Fig. 5. Area planted with spinach in the Salinas Valley of coastal California (solid line) and Santa Clara Valley (dotted line), for the 30 -year period starting in 1980 (Monterey and Santa Clara counties Agricultural Commissioners offices), compared with total amount of spinach consumed in the entire United States for the same time period (Economic Research Service-U.S. Department of Agriculture).

isolated from a variety of hosts grown in coastal California $(4,5)$. This indicates that the fungus is capable of surviving as microsclerotia in coastal California soils and impact subsequent crops, including lettuce.

Since the early 1990s the high demand for bagged spinach has led to a threefold increase in production area (Fig. 5), and the implementation of intensive production practices, whereby up to 9.0 million plants are grown per hectare, and several spinach crops are grown successively in a field each year. This trend has only begun in vegetable production regions outside of the Salinas Valley of coastal California recently; however, most production still occurs in Salinas Valley and accounts for $>75 \%$ of spinach and $\approx 50 \%$ of lettuce produced in the United States. Hence, it is conceivable that Verticillium wilt of lettuce may become prominent in other parts of California, especially if contaminated spinach seed is planted at high density and frequency, similar to the practices in the Salinas Valley. Attempts are currently underway to develop effective seed treatments in spinach that reduce (or eliminate) incidence of $V$. dahliae in seed, which in turn may prevent the establishment of the pathogen and the disease in other lettuce production environments of California.

\section{ACKNOWLEDGMENTS}

We thank the collaborators who contributed isolates of $V$. dahliae from spinach seed produced in various geographic locations, and the various vegetable seed companies that contributed lettuce seed lots for $V$. dahliae assay. The population structure and a portion of the migration analyses were performed using the resources of the Computational Biology Service Unit of Cornell University, which was funded in portion by the Microsoft Corporation. We are also grateful to the California Leafy Greens Advisory Board (contracts 2011-05 and 2011-06) and USDANIFA-SCRI (grant no. 2010-51181-21069) for funding that made this research possible.

\section{LITERATURE CITED}

1. Almany, G. R., De Arruda, M. P., Arthofer, W., Atallah, Z. K., Beissinger, S. R., Berumen, M. L., Bogdanowicz, S. M., Brown, S. D., Bruford, M. W., Burdine, C., Busch, J. W., Campbell, N. R., Carey, D., Carstens, B. C., Chu, K. H., Cubeta, M. A., Cuda, J. P., Cui, Z. X., Datnoff, L. E., Davila, J. A., Davis, E. S., Davis, R. M., Diekmann, O. E., Eizirik, E., Fargallo, J. A., Fernandes, F., Fukuda, H., Gale, L. R., Gallagher, E., Gao, Y. Q., Girard, P., Godhe, A., Goncalves, E. C., Gouveia, L., Grajczyk, A. M., Grose, M. J., Gu, Z. F., Hallden, C., Harnstrom, K., Hemmingsen, A. H., Holmes, G., Huang, C. H., Huang, C. C., Hudman, S. P., Jones, G. P., Kanetis, L., Karunasagar, I., Keyghobadi, N., Klosterman, S. J., Klug, P. E., Koch, J., Koopman, M. M., Koppler, K., Koshimizu, E., Krumbock, S., Kubisiak, T., Landis, J. B., Lasta, M. L., Lee, C. Y., Li, Q. Q., Li, S. H., Lin, R. C., Liu, M., Liu, N., Liu, W. C., Liu, Y., Loiseau, A., Luan, W. S., Maruthachalam, K. K., McCormick, H. M., Mellick, R., Monnahan, P. J., Morielle-Versute, E., Murray, T. E., Narum, S. R., Neufeld, K., de Nova, P. J. G., Ojiambo, P. S., Okamoto, N., Othman, A. S., Overholt, W. A., Pardini, R., Paterson, I. G., Patty, O. A., Paxton, R. J., Planes, S., Porter, C., Pratchett, M. S., Puttker, T., Rasic, G., Rasool, B., Rey, O., Riegler, M., Riehl, C., Roberts, J. M. K., Roberts, P. D., Rochel, E., Roe, K. J., Rossetto, M., Ruzzante, D. E., Sakamoto, T., Saravanan, V., Sarturi, C. R., Schmidt, A., Schneider, M. P. C., Schuler, H., Serb, J. M., Serrao, E. T. A., Shi, Y. H., Silva, A., Sin, Y. W., Sommer, S., Stauffer, C., Strussmann, C. A., Subbarao, K. V., Syms, C., Tan, F., Tejedor, E. D., Thorrold, S. R., Trigiano, R. N., Trucco, M. I., Tsuchiya-Jerep, M. T. N., Vergara, P., van de Vliet, M. S., Wadl, P. A., Wang, A. M., Wang, H. X., Wang, R. X., Wang, X. W., Wang, Y., Weeks, A. R., Wei, F. W., Werner, W. J., Wiley, E. O., Williams, D. A., Wilkins, R. J., Wisely, S. M., With, K. A., Wu, D. H., Yao, C. T., Yau, C., Yeap, B. K., Zhai, B. P., Zhan, X. J., Zhang, G. Y., Zhang, S. Y., Zhao, R., and Zhu, L. F. 2009. Permanent genetic resources added to Molecular Ecology Resources Database 1 May 2009-31 July 2009. Mol. Ecol. Resour. 9:1460-1466.

2. Anonymous. 2008. USDA-NASS. http://www.nass.usda.gov/Publications/ Ag_Statistics/2008/index.asp

3. Atallah, Z. K., Hayes, R. J., and Subbarao, K. V. 2011. Fifteen years of Verticillium wilt of lettuce in America's salad bowl: A tale of immigration, subjugation, and abatement. Plant Dis. 95:784-792.

4. Atallah, Z. K., Maruthachalam, K., du Toit, L., Koike, S. T., Davis, R. M., Klosterman, S. J., Hayes, R. J., and Subbarao, K. V. 2010. Population 
analyses of the vascular plant pathogen Verticillium dahliae detect recombination and transcontinental gene flow. Fungal Genet. Biol. 47:416422.

5. Atallah, Z. K., Maruthachalam, K., Vallad, G. E., Davis, R. M., Klosterman, S. J., and Subbarao, K. V. 2011. Analysis of Verticillium dahliae suggests a lack of correlation between genotypic diversity and virulence phenotypes. Plant Dis. 95:784-792.

6. Beerli, P., and Felsenstein, J. 1999. Maximum likelihood estimation of migration rates and effective population numbers in two populations using a coalescent approach. Genetics 152:763-773.

7. Beerli, P., and Felsenstein, J. 2001. Maximum likelihood estimation of a migration matrix and effective population sizes in $\mathrm{n}$ subpopulations by using a coalescent approach. Proc. Natl. Acad. Sci. 98:4563-4568.

8. Bennett, R. S., Milgroom, M. G., Sainudiin, R., Cunfer, B. M., and Bergstrom, G. C. 2007. Relative contribution of seed-transmitted inoculum to foliar populations of Phaeosphaeria nodorum. Phytopathology 97:584-591.

9. Bergl, R. A., and Vigilant, L. 2007. Genetic analysis reveals population structure and recent migration within the highly fragmented range of the Cross River gorilla (Gorilla gorilla diehli). Mol. Ecol. 16:501-516.

10. Cornuet, J. M., Piry, S., Luikart, G., Estoup, A., and Solignac, M. 1999. New methods employing multilocus genotypes to select or exclude populations as origins of individuals. Genetics 153:1989-2000.

11. Dettman, J. R., and Taylor, J. W. 2004. Mutation and evolution of microsatellite loci in Neurospora. Genetics 168:1231-1248.

12. du Toit, L. J. 2009. Spinach seed production. Paper read at International Spinach Conference, Fayetteville, AR.

13. du Toit, L. J., Derie, M. L., and Hernandez-Perez, P. 2005. Verticillium wilt in spinach seed production. Plant Dis. 89:4-11.

14. Duniway, J. M. 2002. Status of chemical alternatives to methyl bromide for pre-plant fumigation of soil. Phytopathology 92:1337-1343.

15. Evanno, G., Regnaut, S., and Goudet, J. 2005. Detecting the number of clusters of individuals using the software STRUCTURE: A simulation study. Mol. Ecol. 14:2611-2620.

16. Excoffier, L., Laval, G., and Schneider, S. 2005. Arlequin ver. 3.0: An integrated software package for population genetics data analysis. Evol. Bioinfo. Online 1:47-50.

17. Garibaldi, A., Gilardi, G., and Gullino, M. L. 2007. First report of Verticillium wilt caused by Verticillium dahliae on lettuce in Italy. Plant Dis. 91:770-770.

18. Hedrick, P. W. 2005. Genetics of Populations. 3rd ed. Jones and Bartlett Publishers, Sudbury, MA.

19. Hey, J., and Nielsen, R. 2004. Multilocus methods for estimating population sizes, migration rates and divergence time, with applications to the divergence of Drosophila pseudoobscura and D-persimilis. Genetics 167:747-760.

20. Hey, J., Won, Y. J., Sivasundar, A., Nielsen, R., and Markert, J. A. 2004. Using nuclear haplotypes with microsatellites to study gene flow between recently separated Cichlid species. Mol. Ecol. 13:909-919.

21. Jakobsson, M., and Rosenberg, N. A. 2007. CLUMPP: A cluster matching and permutation program for dealing with label switching and multimodality in analysis of population structure. Bioinformatics 23:1801-1806.
22. Ligoxigakis, E. K., Vakalounakis, D. J., and Thanassoulopoulos, C. C. 2002. Weed hosts of Verticillium dahliae in Crete: Susceptibility, symptomatology and significance. Phytoparasitica 30:511-518.

23. Meirmans, P. G., and Van Tienderen, P. H. 2004. GENOTYPE and GENODIVE: Two programs for the analysis of genetic diversity of asexual organisms. Mol. Ecol. Notes 4:792-794.

24. Nei, M. 1973. Analysis of gene diversity in subdivided populations. Proc. Natl. Acad. Sci. 70:3321-3323.

25. Nielsen, R. 2001. Statistical tests of selective neutrality in the age of genomics. Heredity 86:641-647.

26. Nielsen, R., and Wakeley, J. 2001. Distinguishing migration from isolation: A Markov chain Monte Carlo approach. Genetics 158:885-896.

27. Paetkau, D., Slade, R., Burden, M., and Estoup, A. 2004. Genetic assignment methods for the direct, real-time estimation of migration rate: A simulation-based exploration of accuracy and power. Mol. Ecol. 13:5565.

28. Peakall, R., and Smouse, P. E. 2006. Genalex 6: Genetic analysis in Excel. Population genetic software for teaching and research. Mol. Ecol. Notes 6:288-295.

29. Pearse, D. E., and Crandall, K. A. 2004. Beyond FST: Analysis of population genetic data for conservation. Conserv. Gen. 5:585-602.

30. Piry, S., Alapetite, A., Cornuet, J.-M., Paetkau, D., Baudouin, L., and Estoup, A. 2004. GeneClass2: A software for genetic assignment and first-generation migrant detection. J. Hered. 95:536-539.

31. Pritchard, J. K., Stephens, M., and Donnelly, P. 2000. Inference of population structure using multilocus genotype data. Genetics 155:945959.

32. Proctor, M. F., McLellan, B. N., Strobeck, C., and Barclay, R. M. R. 2005. Genetic analysis reveals demographic fragmentation of grizzly bears yielding vulnerably small populations. Proc. R. Soc. B 272:2409-2416.

33. Rannala, B., and Mountain, J. L. 1997. Detecting immigration by using multilocus genotypes. Proc. Natl. Acad. Sci. 94:9197-9201.

34. Rosenberg, N. A. 2004. DISTRUCT: A program for the graphical display of population structure. Mol. Ecol. Notes 4:137-138.

35. Sackston, W. E., and Sedun, F. S. 1982. Verticillium wilt of spinach: A useful experimental system. Can. J. Plant Pathol. 4:310.

36. Snyder, W. C., and Wilhem, S. 1962. Seed transmission of Verticillium dahliae of spinach. Phytopathology 52:365.

37. Subbarao, K. V., Hubbard, J. C., Greathead, A. S., and Spencer, G. A. 1997. Verticillium wilt. Page 26-27 in: Compendium of Lettuce Diseases. R. M. Davis, K. V. Subbarao, R. N. Raid, and E. A. Kurtz, eds. The American Phytopathological Society, St Paul, MN.

38. Vallad, G. E., and Subbarao, K. V. 2008. Colonization of resistant and susceptible lettuce cultivars by a green fluorescent protein-tagged isolate of Verticillium dahliae. Phytopathology 98:871-885.

39. Watterson, G. A. 1977. Heterosis or neutrality? Genetics 85:789-814.

40. Wilhelm, S., Storkan, R. C., and Sagen, J. E. 1961. Verticillium wilt of strawberry controlled by fumigation of soil with chloropicrin and chloropicrin-methyl bromide mixtures. Phytopathology 51:744-748.

41. Zaffarano, P. L., McDonald, B. A., and Linde, C. C. 2009. Phylogeographical analyses reveal global migration patterns of the barley scald pathogen Rhynchosporium secalis. Mol. Ecol. 18:279-293. 